mortality from all causes was $51 \%$ for those with transfusion-associated non-A, non-B hepatitis, compared with $52 \%$ of the controls. In this long-term follow-up study, there was no increase in mortality from all causes after transfusion-associated non-A, non-B hepatitis, although there was a small but statistically significant increase in the number of deaths related to liver disease. In an accompanying editorial, Dr. Albert J. Czaja of the Mayo Clinic notes that the observations of Dr. Seeff et al "heighten our awareness of the disease potential of hepatitis $\mathrm{C}$ infection and provide a realistic hope that dire consequences are unusual."

FROM: Seeff LB, Buskell-Bales Z, Wright EC, et. al. Long-term mortality after transfusion-associated nonA, non-B hepatitis. N Engl J M ed 1992;327:1906-1911.

\section{Clinton Appoints First AIDS Czar}

President Clinton appointed Kristine Gebbie as the first national AIDS coordinator on the eve of dismantling the National AIDS Commission. Clinton said Gebbie would be a full member of the Domestic Policy Council and work closely with the Department of Health and Human Services in coordinating federal AIDS policies.

Gebbie currently serves as a special consultant to the Department of Health and Human Services, and prior to that, she was the administrator for the Oregon Health Division, secretary for the Washington State Department of Health, and a member of President Reagan's Commission on HIV. Since 1989, she also has served as chair of the Centers for Disease Control Advisory Committee for the Prevention of HIV.

On July 21 and 22, more than 50 activists and other representative from national organizations concerned with AIDS met with Kristine Gebbie's office to discuss the agenda and organization framework for consideration by Gebbie.

Although AIDS advocates had criticized the administration for the delay in filling the post, some praised Clinton for selecting Gebbie because of her long history in working to implement positive public health programs to combat HIV transmission and to serve the AIDS community.

\section{Healthcare Worker Reported Dead from Creutzfeldt- Jakob Disease}

A 58-year-old internist was reported to have died of Creutzfeldt-Jakob Disease (CJD). Symptoms of impaired mentation were reported first in May 1990, and within three months the patient died of progressive neurological disease. A brain biopsy revealed spongiform encephalopathy. The patient spent one year in pathology training in 1960 performing numerous postmortem examinations, raising suspicion of possible occupationally acquired infection. The authors of this article summarize 23 additional reported cases of CJD in healthcare workers, including five physicians (two neurosurgeons and a pathologist), four dentists, nine nurses, three nursing assistants, and two histopathology technicians.

CJD is a neurodegenerative disease of the brain characterized by rapidly progressive dementia resulting in death within one year of clinical onset. Because it can be transmitted by infected human tissue, concerns have been raised among healthcare workers about potential occupationally acquired infection.

CJD has a reported worldwide incidence of one to two cases per million population, although it is thought to be underdiagnosed. CJD is believed to be caused by "prions," transmissible agents apparently containing no nucleic acids, differing from all other transmissible agents. CJD also can be genetic in origin and between $5 \%$ and $15 \%$ of identified cases occur in an autosomal-dominant pattern associated with a specific genetic mutation. Neurological tissues also have been associated with transmission of the CJD pathogen, including growth hormone prepared from human pituitary glands and cadaveric dural grafts. The very long latency, which can exceed 30 years, makes it difficult to ascertain the source of infection in sporadic cases. 206. 